\title{
Review
}

\section{The practical implications of the coronary artery surgery trials}

\author{
D G JULIAN \\ From the Department of Cardiology, Freeman Hospital, Newcastle upon Tyme
}

The era of randomised studies of coronary artery bypass surgery ${ }^{1-17}$ has probably come to an end. It is, therefore, opportune to assess the present state of this form of surgery in the light of the information available from these trials.

There is general agreement that coronary artery bypass surgery is effective in relieving angina pectoris, but controversy persists as to whether it can improve prognosis. This topic has recently been extensively reviewed. ${ }^{18-20}$ Both Braunwald ${ }^{18}$ and Hampton ${ }^{19}$ concluded that there is little evidence that coronary artery bypass surgery improves prognosis except in those with severe obstruction of the left main coronary artery, whereas Killip and Ryan ${ }^{20}$ consider that high risk patients with three vessel disease and reduced ventricular function may also benefit. In this review I reconsider the evidence on the effect of coronary artery bypass surgery on prognosis and discuss the practical implications.

\section{"Natural history" of angina pectoris}

Expectations of the potential effect of coronary bypass surgery on prognosis must depend on our knowledge of the natural history of ischaemic heart disease and, in particular, of angina pectoris. Current beliefs are largely rooted in the observations made on patients subjected to coronary arteriography in the 1960s. Since that time, there has been a major fall in the mortality due to ischaemic heart disease in some countries, which suggests that the baseline against which the benefits of surgery can be assessed has altered. Although coronary artery surgery itself might have provided a small contribution to this change, the mortality had started to decline before its introduction and is much greater than would be expected. Has the decline in the mortality of ischaemic heart disease been caused by a reduction in the incidence of the

Requests for reprints to Professor D G Julian, Department of Cardiology, Freeman Hospital, Newcastle upon Tyne NE7 7DN.

Accepted for publication 9 April 1985 disease or by reduced fatality rates? As yet, the answer is obscure, particularly in relation to angina, but some authorities believe that the latter is the case. Thus, Braunwald has written "it is particularly interesting to consider the steadily improving survival rate among medically treated patients with angiographically confirmed three-vessel obstructive coronary-artery disease, a condition that is now widely considered to be an indication for coronary artery bypass grafting, even though the patients are not entirely comparable. The annual mortality rate for such patients was $11.4 \%$ in the late 1960s [reported by Reeves et al], $4.8 \%$ in the early and mid 1970s (in the Veterans Administration study described by Murphy et $a^{4}$ ), 3.5\% in the European Coronary Artery Surgery Study in the late $1970 \mathrm{~s}^{10}$ and only $2 \cdot 1 \%$ in the recently reported CASS Study (sic). ${ }^{15}$ Comparable improvements in the prognosis have occurred among medically treated patients with one or two vessel disease and normal or impaired left ventricular function."18 Braunwald suggests that the remarkable fall in death rate could be due to the use of beta blockers and calcium antagonists. There is, however, no evidence that calcium antagonists improve prognosis, and it is of interest that beta blockers were given to a higher proportion of the medically treated patients in the European study than in the Coronary Artery Surgery Study (CASS).

In fact, comparisons of prognosis over time, such as those above, are very misleading and it is probable that the apparent decline in the annual mortality of angina is largely spurious. ${ }^{21}$ In comparing the mortality in medical patients in the European study and in CASS, it is instructive to compare the four year survival of all (that is, non-randomised as well as randomised) medically treated patients in CASS with the medically treated patients in the European study. In patients with good left ventricular function, the findings are remarkably similar-the survival rate of $94 \%$ as opposed to $93 \%$ for two vessel disease and $82 \%$ versus $84 \%$ for three vessel disease respectively. ${ }^{13}$

The perceived indications for coronary arteriography have changed strikingly with time. Initially, 
coronary arteriography was thought to be indicated only in those with prolonged disability caused by intractable angina. In recent years, and particularly in the United States, the mere suspicion of angina pectoris has been a major indication for this investigation. Thus patients have been studied much earlier in the development of their disease; this in itself (if survival is calculated from angiography to death) produces an apparent "improvement" in outcome because of what has been called a "lead time bias". ${ }^{21}$

Finally, the criteria for inclusion in the studies quoted above were different in many important respects including the age and sex structure of the populations, the presence or absence of concomitant disease, and the exclusion criteria. Thus any claim that there has been an improvement in the "natural history" on angina pectoris over the last 15 or 20 years is speculative.

Numerous studies have shown the importance of the severity of coronary disease and of left ventricular dysfunction in determining outlook. ${ }^{21} 22$ These have been further confirmed in the three randomised studies (CASS and Veterans Administration and European studies). In stressing the importance of these variables, however, it is essential not to overlook other prognostic factors. Evidence is accumulating that stress induced ischaemia, demonstrated either subjectively or objectively, contributes to prognosis. It has been too readily assumed that patients with apparently similar anatomy and resting ventricular function have the same prognosis, but examination of the CASS data makes it clear that this is quite untrue. Patients with three vessel disease and good left ventricular function included in the CASS randomisation trial ${ }^{13}$ had a much better outlook than those excluded from it on the basis of symptoms. ${ }^{15}$

Several published studies have examined the prognostic importance of symptoms in relation to angiographic findings. Thus Webster $e t$ al found that functional disability was related to mortality rates for each of the groups with one, two, and three vessel disease. ${ }^{23}$ Cohn et al also found that the survival of patients with coronary artery disease was inversely related to the severity of symptoms. ${ }^{24}$ An intriguing but unanswered question is whether those who have had severe symptoms have a better prognosis if medical treatment renders the symptoms mild.

Perhaps even more predictive than symptoms is the result of an exercise test as shown by exercise capacity, ST depression, or a decreased ejection fraction. Even in the presence of three vessel disease, patients who can achieve high levels of exercise have an excellent prognosis. ${ }^{25-27}$ On the other hand, exercise induced ischaemia, as shown by one of the variables mentioned or a combination of them, is associated with a much increased mortality. ${ }^{27} 28$

\section{Randomised trials}

Although useful information has been accumulated from non-randomised trials, three relatively large, well designed randomised trials of coronary artery surgery provide more reliable evidence of prognostic effects. Superficially, the findings of the three trials differ strikingly from one another. The first report, the Veterans Administration study of stable angina, originally concerned 1015 patients recruited between 1970 and 1974. Because of an unacceptably high mortality in the early part of the series, subsequent reports have concentrated on the 686 men randomly allocated to medical or surgical treatment in 1972 to 1974. Analysis at six years showed no difference in overall survival between medically and surgically assigned patients.

In the European study 768 men were recruited between 1973 and 1976 . At five years, $83.7 \%$ of those randomised to medical treatment had survived compared with $92.4 \%$ of those randomised to surgery $(\mathbf{p}<0.001)$.

In the CASS report, patients were randomised to surgery between 1975 and 1979. A total of 780 patients (74 of whom were female) were entered: At five years, there was a $92 \%$ chance of survival in the medical group compared with $95 \%$ in the surgical group. ${ }^{16}$ This difference was not statistically significant.

The apparent discrepancies in the results from these three trials have led to much confusion. Are they explicable, and can we draw some conclusions about the effect of coronary artery bypass surgery on prognosis? Hampton, at least, has few doubts. He writes, "the Coronary Artery Surgery Study was a better trial than the European Study. Probably thet patients admitted to the two studies were similar, but we cannot be certain because the severity of angina in the European patients was poorly defined. Allowing for the differences in operative mortality, the outcome in the patients treated surgically was similar in the two studies. The difference between the patients treated medically and surgically in the European Study was probably due to the mortality among the patients treated medically being 'too high'. It seems reasonable to base our clinical practice on the results of CASS: patients whose angina is not adequately controlled should be considered for surgery, but those who can climb a flight of stairs without pain can be treated medically, for there is no good evidence that surgery will prolong their lives." 19

Other interpretations of the data are, however, possible.

\section{Aims of the studies}

Conceptually, there are two quite different kinds of 
question that might be answered in assessing the prognostic effect of coronary bypass surgery in patients with ischaemic heart disease.

The explicative question "Does surgery improve the prognosis of patients with ischaemic heart disease in whom surgery is a reasonable option?" could be asked about the whole group of patients in whom surgery is a reasonable option or about certain defined subsets. Because of the nature of the question, it would be vital in such a study that patients do not deviate from the treatment to which they are randomised-any crossover of subjects from one to the other would contravene the concept of the study and diminish its value. This is clearly a very important question in patients for whom surgery is indicated on the basis of symptoms. If we submit a patient to surgery because of symptoms refractory to medical treatment are we improving (or worsening) his prognosis?

The pragmatic question "In patients in whom surgery is neither absolutely indicated nor absolutely contraindicated would an "aggressive" policy of immediate surgery prove superior in terms of prognosis to a "conventional" approach with medical treatment in the first place, reserving surgery for those whose symptoms demand it?" is, in essence, the question which physicians and cardiologists face in their day to day practice and to which a practical answer is required. In such a study, the crossover from medical to surgical treatment does not constitute a deviation from protocol but is merely an aspect of the conservative approach to treatment of many cardiologists.

It is highly desirable in designing a trial to state which of these two concepts lies behind it. The Veterans Administration trial was concerned with the first concept. Although it is not stated, it seems that the CASS group was also trying to answer the first question, since patients who were potential candidates for surgery on the basis of symptoms were deliberately excluded; indeed, a high proportion of patients had virtually no symptoms. Despite this, there was a very substantial crossover, which made an answer to the first question unobtainable.

The European trial, on the other hand, was very clearly and explicitly addressed to the second question. As in the CASS report, a substantial proportion of patients crossed over, but these should not be regarded as deviants from the protocol, as such a finding was foreseen and was taken into account in the trial design.

\section{Statistical basis for trials}

It is clearly desirable when setting out on a clinical trial to state the statistical principles on which the trial is based, including what number of patients is considered necessary, what reduction in mortality is expected, and what the power of the study is. The duration of the study should also be stated. In criticising the CASS and European studies, Hampton writes, "The numbers of patients in the two studies were similar. It is not clear in either case whether this number was calculated in advance as being adequate."19 Unfortunately, Hampton does not seem to have consulted the key papers in which the basic concepts and methods of the three studies were published. 3712

I have been unable, from the baseline article from the Veterans Administration Study, ${ }^{3}$ to determine the statistical principles on which the size of the study was determined, only that "A sufficiently large number of patients must be studied to ensure that statistically significant differences can be evaluated in objectively identified sub-groups. In a chronic disease such as stable angina, a follow-up time of five years is desirable."

In the statistical section of the protocol of the European Multicentre Coronary Bypass Study calculations of sample size were made to take into account annual mortality rates of $2-8 \%$. Eventually, it was estimated that a total of approximately 700 patients was needed in the two groups ${ }^{7}$; at the outset the follow up period was defined as five years.

In the CASS report, detailed consideration was given to the expected mortality and sample size. ${ }^{12} \mathrm{~A}$ review of available data at the time that CASS was initially designed suggested that the annual medical mortality in patients with confirmed coronary disease would be about $4 \%$. Calculations were published estimating the statistical power of CASS to detect clinically important differences in survival for assumed annual medical mortalities of $2 \%$ and $4 \%$ respectively, and assuming a percentage reduction in mortality due to surgery of $50 \%$ or $30 \%$ respectively. Calculations were based on samples sizes of 750 and 800 patients; the follow up period was defined as five years.

The number of patients entered into the European and CASS studies was, therefore, chosen in advance and successfully achieved. In the case of CASS, the mortality encountered in the medical group was much lower than that predicted so that a very much larger number of patients would have had to have been recruited to show a statistically significant result. Indeed, even if the study had shown a statistically significant difference it is doubtful whether any benefit shown could be regarded as being of clinical importance in a group with such a low mortality.

It is now generally recognised that it is desirable that the original population from which the trial patients are drawn is defined. This is a defect of the European trial, whereas in the Veterans Administra- 
tion trial the group of 1015 patients was derived from 5538 patients with stable angina who were screened and of whom 2196 were entered into the arteriographic logs. In CASS, 24959 patients were entered into the register at 15 clinical centres. Only 11 of these centres participated in the randomised trial, and they screened 16626 registered patients to determine their eligibility for the randomised trial. Patients were excluded on the basis of normal or minimal disease (28.3\%), the absence of operable vessels $(4.9 \%)$, class III or IV angina (36.5\%), left main coronary artery disease (1.5\%), and other exclusions (such as previous coronary surgery, heart failure, or old age) (16.1\%). Thus of the original patients, $12.7 \%$ were eligible for randomisation but only 780 of the total-that is, about $5 \%$ were eventually randomised. Although the registry has provided us with much valuable data, questions remain over the applicability of the categorisations outlined in CASS to usual clinical practice. Thus the numbers of patients screened (denominator) relate essentially to those patients who between 1975 and 1979 were considered at 11 centres in the United States as having indications for coronary arteriography. Nowhere are the indications for arteriography discussed. The indications in the United States would have been quite different from those in other countries at the time of the study. For example, large numbers of patients who were symptomless after myocardial infarction were studied as were many patients with minimal angina. Few similar patients in the United Kingdom would have been subjected to coronary arteriography at that time. Furthermore, it is clear that the indications for coronary arteriography have changed in the United States recently, perhaps as a result of CASS. The relevance and future applicability of the baseline is, therefore, questionable. Another curious feature of CASS is the exclusion of patients with class III or IV angina, whether or not they had been treated medically. It is widely accepted that the overwhelming majority of patients with class III or IV angina pectoris can have their symptoms controlled by contemporary medical treatment. Thus a very large number of patients who with medical treatment would have been in class I or II have been excluded from the study because it was thought that surgery might, at some future date, be needed to relieve their symptoms. In fact a high proportion of these cases were not submitted to surgery during the succeeding five years. Information about outcome in these patients is available from registry data, but is noteworthy that their prognosis was worse than that of the class I or II patients actually included.

\section{Baseline characteristics}

The object of randomisation is to ensure a balance of important prognostic characteristics in treatment groups. In this regard each of the three studies is satisfactory, and within each study the patients allocated to medical and surgical management were similar in essential characteristics. There are, however, striking (and deliberate) differences between the studies (Table). There are some important differences between the data provided in this Table and those shown in the apparently similar Table 2 of Hampton's report, ${ }^{19}$ which contained numerous errors, as pointed out by Varnauskas. ${ }^{29}$

It will be observed that the criteria for the duration and treatment of angina pectoris are more precisely defined in the Veterans Administration and European studies than in CASS, beta blockade was in more widespread use in the European Study than in CASS and the severity of angina was much greater in the European and Veterans Administration studies than

Baseline camparisons. Figures are percentages of patients unless stated otherwise

\begin{tabular}{|c|c|c|c|}
\hline & VA study & European study & CASS \\
\hline $\begin{array}{l}\text { Duration of angina (months) } \\
\text { Previous medical treatment obligatory } \\
\text { Current beta blocker treatment } \\
\text { Current smoking } \\
\text { Previous myocardial infarction } \\
\text { Severity of angina: }\end{array}$ & $\begin{array}{l}6 \\
\text { Yes } \\
? \\
? \\
60\end{array}$ & $\begin{array}{r}3 \\
\text { Yes } \\
74 \\
43 \\
46\end{array}$ & $\begin{array}{l}\text { No requirement } \\
\text { No } \\
43 \\
40 \\
60\end{array}$ \\
\hline $\begin{array}{l}\text { None } \\
\text { Class I } \\
\text { Class II } \\
\text { Class III } \\
\text { Class IV } \\
\text { Cinction }\end{array}$ & $\begin{array}{r}0 \\
3 \\
39 \\
55 \\
3\end{array}$ & $\left\{\begin{array}{l}0 \\
57^{\star} \\
42 \\
0\end{array}\right.$ & $\begin{array}{l}21 \\
20 \\
59 \\
0+\end{array}$ \\
\hline $\begin{array}{l}\text { Ejection fraction: } \\
\geqslant 45 \% \\
\geqslant 50 \%\end{array}$ & $\frac{80}{-}$ & $\overline{100}$ & $\overline{74}$ \\
\hline $\begin{array}{l}\text { Coronary arteriography: } \\
1 \text { vessel disease } \\
2 \text { vessel disease } \\
3 \text { vessel disease } \\
\text { Left main stem disease }\end{array}$ & $\begin{array}{l}16 \\
33 \\
51 \\
11\end{array}$ & $\begin{array}{r}0 \\
39 \\
53 \\
8\end{array}$ & $\begin{array}{r}27 \\
41 \\
32 \\
0\end{array}$ \\
\hline
\end{tabular}

VA, Veterans Administration.

*Classes I and II. † Classes III and IV. 
in CASS. The CASS patients had two prognostically disadvantageous features-they had a somewhat lower ejection fraction and their criteria for arterial obstruction were more strict.

\section{Quality of surgery}

In the assessment of a surgical method of treatment, the quality of the surgery and the associated management is obviously of importance. In studies such as those reviewed here, standards equivalent to those encountered in the general run of good cardiac surgical units would be hoped for. Throughout the period of the three studies improvements were constantly taking place in several areas of surgical management. Techniques of myocardial preservation were being improved, a higher proportion of diseased vessels were being grafted, and graft patency rates were increasing. It would, therefore, be expected that mortality and morbidity would be progressively reduced, and this was, indeed, reflected in the reported results. In the Veterans Administration study, 30 day operative mortality was $5.8 \%$ and the vein graft patency rate at one year was $69 \%$. In the European study, operative mortality was $3.6 \%$ and vein graft patency was reported to be $90 \%$ at or before nine months and $77 \%$ between nine and 18 months. In CASS, operative mortality was $1.4 \%$, and the number of grafts per patient was higher than in the European study. Graft patency in 129 patients assessed within 60 days was $90 \%$.

It is probable that present surgical practice in most centres corresponds fairly closely with the results reported in CASS. It is generally accepted that the mortality and the graft closure rate as well as the number of grafts used in the Veterans Administration study were such as to make the observations inapplicable to present surgical practice. Because of the unsatisfactory surgical experience in the Veterans Administration study, the rest of this review is concerned largely with the European study and CASS.

\section{Quality of medical treatment}

This is difficult to assess in the trials except in the case of beta blockers, but these drugs are almost certainly the most important in relation to prognosis. A substantially higher proportion of the patients in the European trial $(74 \%)$ were receiving beta blockers at baseline than in CASS (43\%), and there was higher utilisation of these drugs in "medical" patients throughout the European trial than in CASS. In both trials, approximately two thirds of "medical" patients and one third of "surgical" patients received beta blockers. (If, as some workers suggest, ${ }^{18} 19$ beta blockers have a profound effect on prognosis, and surgery has none, it is difficult to see why in both studies the mortality in the medical groups was not lower than that in the surgical.

\section{Results}

As both the European study and CASS had a primary endpoint of five years, it seems most appropriate to consider this time interval when comparing the overall results.

In the European study, at five years $7.6 \%$ of the surgical and $16.4 \%$ of the medical cases had died-a $53 \%$ reduction in mortality $(p=0.00025)(95 \%$ confidence interval $30-71 \%) .{ }^{10}$ In CASS, the risk of death was $5 \%$ for those treated surgically compared with $8 \%$ for those treated medically. The $95 \%$ confidence interval lies between a $61 \%$ reduction in mortality and a $13 \%$ increase. ${ }^{19}$ There is, therefore, an overlap in the confidence limits, meaning that the two studies are statistically compatible. If the results were pooled, as has been common practice with other trials of ischaemic heart disease, the results of statistical analysis would strongly favour surgery. As discussed by the CASS investigators, the excellent long term result in CASS patients assigned to medical treatment reduces the power of the experiment to detect a reduction in mortality afforded by prompt elective coronary artery bypass surgery. Indeed, because of the low power of the randomised section of CASS, essentially no deductions can be made about the effect of cardiac surgery on the prognosis of patients resembling those included (or indeed any other patients).

\section{Subset analysis}

As is often pointed out by the critics of controlled trials, there are dangers in subset analysis, particularly if these are defined retrospectively. When subsets have been defined in advance as an intrinsic part of the study they are valid provided that the appropriate statistical considerations are respected.

The subset finding that has been most widely accepted is that from the Veterans Administration study in which a significant reduction in mortality was observed in patients with disease of the left main coronary artery. ${ }^{1}$ The four year mortality in the 44 patients treated medically was $33 \%$ compared with $7 \%$ in 46 patients treated surgically. The numbers studied were small, and the confidence limits of this finding were wide. None the less, it has achieved widespread acceptance because of confirmatory evidence from other sources.

In the European study, at five years there was a statistically significant reduction $(p=0.0003)$ in mortality in patients with three vessel disease treated surgically, with a $6 \%$ death rate in those treated surgi- 
cally compared with $17.6 \%$ in those treated medically. There was no difference in mortality in those with two vessel disease. In a subgroup of patients with a greater than $50 \%$ stenosis in the proximal third of the anterior descending artery, however, whether as a component of two or three vessel disease, there was a highly significant difference between the two survival curves, with the mortality at five years being reduced by $60 \%$. Other specific subsets of patients who seemed to benefit from surgery were those with an abnormal resting electrocardiogram and those with peripheral arterial disease.

Of particular interest was the finding that prognosis was not improved in those with little or no ST depression on an exercise test, whereas in those who had ST depression of $\geqslant 0.15 \mathrm{mV}$, the mortality in the medical group at five years was $21 \%$ compared with $8.3 \%$ in the surgical group, a reduction of $60 \%$.

In CASS no subsets appeared to benefit from surgical intervention at five years but analysis after a further 14 months of follow-up revealed a significantly greater survival rate in surgically assigned patients with three vessel disease and impaired ventricular function $(p<0.01){ }^{20}$

\section{Summary of the trials}

All three studies were well designed and used expert statistical advice. The chief defect of the European study was the absence of information about the original population from which the trial patients were drawn. The major defect of the CASS randomisation trial was its low power because of the randomisation of a number of patients which proved to be too small because of the low mortality of the control group.

The striking differences in prognosis of the medically treated patients can be accounted for by their different baseline characteristics rather than by progressively improving medical prognosis ${ }^{18}$ or the "spuriously high" mortality in the conservatively treated patients in the European trial.

The Veterans Administration trial, which attempted to answer the explicative question "Does surgery improve prognosis in patients with angina?" cannot be used as a guide to present practice as the surgical management was substantially poorer than is usual today.

The European trial was confined to men with angina in the presence of two or three vessel coronary disease and an ejection fraction $\geqslant 50 \%$. It considered the question "Does a policy of immediate surgery for such patients result in a better prognosis than does the conventional practice of reserving surgery for those whose symptoms become intolerable?" and gave an unequivocal answer of "yes." Subset analysis, however, suggests that surgery does not benefit those with two vessel disease, particularly if the proximal left anterior descending coronary artery is not involved, nor those with a normal or near normal exercise test.

If an answer, from this study, to the explicative question "Does surgery improve prognosis in patients with angina?" is to be attempted, it must be realised that the study was heavily biased against showing any beneficial effect of surgery for the following reasons. First, patients who died after assignment to surgery but who had, in fact, received only medical treatment were included in the surgical group. Secondly, the medical patients received prognostically better medical treatment in that two thirds of them received beta blockers compared with only one third of the surgical patients. Thirdly, a relatively high risk subgroup of the medical patients (those in whom more symptoms developed) received the "benefit" of surgery but were retained within the medical group.

The CASS registry has provided invaluable information about prognosis in patients who had coronary arteriography during the study period. A most important observation was that a very low risk group of patients with ischaemic heart disease can be identified on clinical grounds alone. Thus if patients have never had severe symptoms and have good left ventricular function at rest and on exercise they have an excellent prognosis which it would be impossible to improve appreciably with surgery. Whether the same is true of the large group of patients who have had severe symptoms that can be rendered mild by medical treatment is impossible to say.

The CASS randomisation trial contributes nothing whatsoever to our knowledge of the effect of surgery on prognosis in angina. The negative result of the study could well be due to a type II error. Even if the study had been positive and shown, for example, a $30 \%$ reduction in five year mortality, the clinical significance of such a finding would be dubious. We cannot, therefore, as has been suggested, 1819 base our clinical practice on the results of the CASS randomisation trial.

\section{Practical implications in regard to indications for coronary artery bypass surgery}

Coronary artery surgery is undoubtedly effective in relieving angina pectoris provided that the coronary arterial lesions are technically suitable for the bypass procedure. There is widespread agreement that surgery is indicated for those in whom medical treatment has failed, but this apparent consensus conceals very wide variations in practice. The great differences between the use of coronary artery bypass surgery in the United States and other countries probably reflects not only superior resources in the former but also a different attitude as to what is acceptable in 
terms of symptoms. For example, in the United States angina which prevented a patient, of whatever age, from playing golf would be considered unacceptable and regarded as an indication for surgery. By contrast, in other countries the cardiologist weighs up the patient very carefully before considering operative intervention and, consciously or subconsciously, takes into account such factors as age, occupation, employability, and life style. Many patients come into a borderline zone, and in these the physician attempts, as far as he can, to avoid surgery in the hope that time or modifications in medical treatment will achieve a situation that is tolerable, if not ideal. It is particularly in such patients that knowledge about the effect of surgery on prognosis is relevant, as the probability of an improvement in life expectancy would often tip the balance in favour of a surgical as opposed to a medical approach. This poses a particular problem for the physician in district hospitals who does not have immediate access to coronary arteriography.

When all the evidence is put together, there is little to indicate the need for coronary arteriography in the patient who has never had symptoms that are more than mild and who performs an exercise test with little difficulty. On the other hand, those who have had more severe symptoms, or who have adverse features on an exercise test (such as a low exercise work capacity, readily induced ST depression of $\geqslant 0.1 \mathrm{mV}$, or a fall in ejection fraction) should be assessed by coronary arteriography. If this investigation shows three vessel disease or two vessel disease with a very proximal left anterior descending lesion, coronary artery bypass surgery should be seriously considered. Clearly, factors such as age and the attitude of the patient must be taken into account in deciding on investigation or surgery.

\section{The future}

Changes are taking place in the management of ischaemic heart disease that may alter these conclusions.

The introduction of new drugs and improvements in methods of managing life style could reduce the mortality in medically treated patients. As yet, there is no evidence that calcium antagonists improve prognosis, and there is no proof that risk factor control, other than the cessation of smoking, improves life expectancy.

The development of coronary angioplasty is clearly an important new factor in the management of angina pectoris. As yet, its effect on prognosis has not been established.

Changes are also taking place in the surgical management of coronary disease. In particular, techniques of myocardial preservation have resulted in much bet- ter results in patients with low ejection fraction. Another important development has been the increasing use of internal mammary artery implants. Evidence suggests that graft patency rates are higher and the long term results are better with this technique than with saphenous vein bypass surgery.

\section{Conclusion}

We can be reasonably confident that surgery improves prognosis in certain groups of patients with ischaemic heart disease. The ones most likely to benefit are those with disease of the left main coronary artery and those with three vessel disease or two vessel disease in which the proximal left anterior descending artery is involved. Coronary arteriography alone, however, provides an inadequate guide to prognosis, as it seems that surgery is most helpful when such anatomical features are accompanied by evidence of left ventricular dysfunction at rest or on exercise.

Physicians should consider the possible beneficial effects of surgery on prognosis in all patients with angina. In doing so, they should take into account symptoms and non-invasive indices of left ventricular function, particularly response to exercise. If these features indicate a substantially worsened prognosis, coronary arteriography should be undertaken if a surgical approach seems a reasonable option.

\section{References}

1 Takaro T, Hultgren HN, Lipton MJ, et al. The VA cooperative randomized study of surgery for coronary arterial occlusive disease II. Subgroup with significant left main lesions. Circulation 1976; 54(suppl 3): 107-17.

2 Detre $\mathrm{K}$, Murphy ML, Hultgren $\mathrm{H}$, et al. Effect of coronary bypass surgery on longevity in high and low risk patients. Lancet 1977; ii: 1243-5.

3 Detre KM, Hultgren HN, Takaro T, et al. Veterans Administration Cooperative Study of Surgery for Coronary Arterial Occlusive Disease III. Methods and baseline characteristics including experience with medical treatment. Am ₹ Cardiol 1977; 40: 212-25.

4 Murphy ML, Hultgren HN; Detre K, et al. Treatment of chronic stable angina: a preliminary report of survival data of the randomized Veterans Administration Cooperative Study. N Engl f Med 1977; 297: 621-7.

5 Detre K, Peduzzi PHP, Murphy M, et al. Effect of bypass surgery on survival in patients in low- and highrisk subgroups delineated by the use of simple clinical variables. Circulation 1981; 63: 1329-38.

6 Takaro T, Hultgren HN, Detre KM, Peduzzi P. The Veterans Administration Cooperative Study of Stable Angina. Current status. Circulation 1982; 65(suppl 2): 60-7.

7 Varnauskas E, Olsson SB. The European Multicenter CABG Trial. In: Yu PN, Goodwin JF, eds. Progress in cardiology 6. Philadelphia: Lea and Febiger, 1977: 83-9.

8 European Coronary Surgery Study Group. Coronary- 
artery bypass surgery in stable angina pectoris: survival at 2 years. Lancet 1979; i: 889-93.

9 European Coronary Surgery Study Group. Prospective randomised study of coronary artery bypass surgery in stable angina pectoris. Lancet 1980; ii: 491-5.

10 European Coronary Surgery Study Group. Long-term results of prospective randomised study of coronary artery bypass surgery in stable angina pectoris. Lancet 1982; ii: 1173-80.

11 European Coronary Surgery Study Group. Survival, myocardial infarction, graft patency and retirement from work in a prospective randomized study of coronary bypass surgery. Circulation 1985: in press.

12 Principal Investigators of CASS and their Associates. National Heart, Lung, and Blood Institute Coronary Artery Surgery Study (CASS). Circulation 1981; 63(suppl 1): 1-81.

13 Mock MB, Ringqvist I, Fisher LD, et al. Survival of medically treated patients in the Coronary Artery Surgery Study (CASS) registry. Circulation 1982; 66: 562-8.

14 CASS Principal Investigators and their Associates. Coronary Artery Surgery Study (CASS): a randomized trial of coronary artery bypass surgery. Quality of life in patients randomly assigned to treatment groups. Circulation 1983; 68: 951-60.

15 CASS Principal Investigators and their Associates. Coronary Artery Surgery Study (CASS): a randomized trial of coronary artery bypass surgery. Survival data. Circulation 1983; 68: 939-50.

16 CASS Principal Investigators and their Associates. Myocardial infarction and mortality in the Coronary Artery Surgery Study (CASS) randomized trial. $N$ Engl F Med 1984; 310: 750-8.

17 CASS Principal Investigators and their Associates. Coronary Artery Surgery Study (CASS): a randomized trial of coronary artery bypass surgery. Comparability of entry characteristics and survival in randomized patients and non-randomized patients meeting randomization criteria. f Am Coll Cardiol 1984; 3: 114-28.
18 Braunwald E. Effects of coronary artery bypass grafting on survival: implications of the randomized Coronary Artery Surgery Study. N Engl $\mathcal{F}$ Med 1983; 309: 1181-4.

19 Hampton JR. Coronary artery bypass grafting for the reduction of mortality: an analysis of the trials. Br Med $\mathcal{F}$ 1984; 289: 1166-70.

20 Killip T, Ryan TJ. Randomized trials in coronary bypass surgery. Circulation 1985; 75: 418-21.

21 Goldman L, Mudge GH Jr, Cook EF. The changing "natural history" of symptomatic coronary artery disease: basis versus bias. Am $\mathcal{F}$ Cardiol 1983; 51: 449-54.

22 Bruschke AVG, Proudfit WL, Sones FM Jr. Progress study of 590 consecutive non surgical cases of coronary disease followed 5 to 9 years. Circulation 1973; 47: 1147-53.

23 Webster JS, Moberg C, Rincon C. Natural history of severe proximal coronary artery disease as documented by coronary cineangiography. Am F Cardiol 1974; 33: 195-200.

24 Cohn PF, Harris P, Barry WH, Rosati RA, Rosenbaum $P$, Waternaux C. Prognostic importance of anginal symptoms in angiographically defined coronary artery disease. Am F Cardiol 1981; 47: 233-7.

25 Bruce RA, DeRouen T, Peterson DR, et al. Noninvasive predictors of sudden cardiac death in men with coronary heart disease: predictive value of maximal stress testing. Am $\mathcal{F}$ Cardiol 1977; 39: 833-40.

26 McNeer JF, Margolis JR, Lee KL, et al. The role of the exercise test in the evaluation of patients for ischemic heart disease. Circulation 1978; 57: 64-70.

27 Bonow RO, Kent KM, Rosing DR, et al. Exercise induced ischemia in mildly symptomatic patients with coronary artery disease and preserved left ventricular function. $N$ Engl f Med 1984; 311: 1339-45.

28 Gohlke H, Samek L, Betz P, Roskamm H. Exercise testing provides additional prognostic information in angiographically defined subgroups of patients with coronary artery disease. Circulation 1983; 68: 979-85.

29 Varnauskas E. Coronary bypass surgery for the reduction of mortality: an analysis of the trials. $\operatorname{Br} M e d ~ \mathcal{F} 1985 ; 290$ : 465 . 